\title{
iLibras como facilitador na comunicação efetiva do surdo: uma ferramenta colaborativa móvel
}

\author{
Simone Erbs da Costa ${ }^{1}$, Carla Diacui Medeiros Berkenbrock ${ }^{1}$, \\ Fabiola Sucupira Ferreira Sell ${ }^{1}$, Gian Ricardo Berkenbrock ${ }^{2}$ \\ ${ }^{1}$ Universidade do Estado de Santa Catarina (UDESC) Joinville - SC - Brasil \\ ${ }^{2}$ Universidade Federal de Santa Catarina (UFSC) Joinville - SC - Brasil \\ si.gen@terra.com.br, carla.berkenbrock@udesc.br, \\ fabiola.sell@udesc.br, gian.rb@ufsc.br
}

\begin{abstract}
Resumo. A comunicação é a forma de compartilhar informação, desenvolver cultura e interagir na sociedade. As tecnologias computacionais em conjunto com Sistemas Colaborativos (SC) contribuem na acessibilidade comunicacional das pessoas e no processo inclusivo. O presente trabalho apresenta uma abordagem para apoiar a comunicação de pessoas surdas e também usuários de Libras por meio de ferramentas computacionais móveis e colaborativas. São adotadas as abordagens da metodologia da pesquisa de Design Science Research (DSR) e Participativo (DP). Dessa forma, foi possível compreender melhor os usuários, bem como construir os recursos computacionais para facilitar a comunicação com surdos.
\end{abstract}

\begin{abstract}
Communication is the way to share information, develop culture and interact in society. Computing technologies together with Collaborative Systems (CS) have contributed to the communication accessibility of the people and in the inclusive process. This research presents an approach to support the communication of deaf people and users of Libras by means of collaborative and mobile computing tools. The approaches Design Science Research (DSR) and Participative (PD) are adopted. Therefore, it was possible to better understand the users as well as to build computing resources to facilitate the communication with the deaf.
\end{abstract}

\section{Introdução}

A comunicação é utilizada pelos seres humanos desde o início da sua existência, sendo a linguagem (fala, escrita ou sinais) a principal forma de o homem transferir conhecimento e interagir na sociedade em que vive ao se comunicar. Onde existe linguagem, existe comunicação, pois a linguagem está associada aos fenômenos comunicativos. A linguagem é a maneira pela qual o conhecimento é adquirido, e na qual o homem expressa suas ideias, pensamentos, mensagens e sentimentos.

A aquisição dessa linguagem é algo complexo. Existe uma relação no ato de falar e compreender, e de ler e escrever. O conhecimento da linguagem da fala é o alicerce da leitura e o canal de comunicação mais utilizado pelas pessoas ao se comunicarem. Para Gadamer (2002, p. 176) "é aprendendo a falar que crescemos, conhecemos o mundo, conhecemos as pessoas e por fim conhecemos a nós próprios.”. Assim, para que uma 
pessoa possa se comunicar, vários fatores estão envolvidos, como: gestos, sons, escritas e imagens são necessários. Os problemas de audição vão além dos problemas de não ouvir, estão relacionados com o desenvolvimento da pessoa.

Pessoas com necessidades especiais possuem mais dificuldades ao se comunicarem devido à a ausência ou problemas em um ou mais dos sentidos. Nesses casos, se faz necessário utilizar mais de uma linguagem, ou seja, mais de um canal de comunicação, ocorrendo os problemas de falhas e as dificuldades (ruídos) de comunicação. A perda dessa comunicação natural é o maior prejuízo do surdo ou pessoas com problemas na audição, já que para se ter uma comunicação efetiva é fundamental utilizar o mesmo canal de comunicação (ROSA, 2009).

Alguns pesquisadores, visando reduzir as barreiras de acesso à comunicação, bem como apoiar a comunicação das pessoas surdas, tecem algumas considerações. Nascimento, Fortes e Kessler (2015) colocam que a utilização de recursos tecnológicos em conjunto com as devidas estratégias promovem o aprender de forma interativa, propiciando, assim, uma melhor comunicação do surdo. Para Trindade (2013, p. 4) "atividades colaborativas têm relevância para a formação humana, social, histórica, e política e podem contribuir para a construção do conhecimento e da identidade do surdo.”.

A comunicação, conforme Pimentel, Gerosa e Fuks (2012) é um dos pilares dos Sistemas Colaborativos (SC); contudo, ela é mais umas das barreiras enfrentadas pelas pessoas surdas. Neste sentido, a popularização das TDIC e o uso crescente dos dispositivos móveis têm causado um grande impacto na sociedade, mudando a forma de as pessoas interagirem e estabelecerem suas relações pessoais. Para Machado et al. (2016), esse avanço tecnológico e o uso dos dispositivos móveis em SC criam um ambiente interativo e motivador, propício para se trabalhar de forma colaborativa. Tendo em vista apoiar esse ambiente em um sistema computacional colaborativo que trate as questões relacionadas com a comunicação, coordenação e cooperação, neste trabalho será utilizado o Modelo 3C (M3C) de colaboração (PIMENTEL et al., 2006).

Neste tocante, desenvolver condições de acessibilidade comunicacional bilíngue de pessoas surdas pode ser uma das estratégias para lhes garantir melhores condições de acesso às informações e à comunicação. As Tecnologias Digitais da Comunicação e Informação (TDIC) potencializam a acessibilidade comunicacional. Por meio delas é possível criar conteúdos digitais com múltiplas linguagens e mídias, onde as TDICs podem ser utilizadas como Tecnologias Assistivas (TA).

O presente trabalho apresenta uma abordagem para apoiar a comunicação de pessoas surdas e usuários de Língua Brasileira de Sinais - Libras por meio de ferramentas computacionais móveis e colaborativas. A hipótese é que a revolução digital e da informação em conjunto com os $\mathrm{SC}$ e as tecnologias adaptativas criem ambientes propícios para interagir e se relacionar de forma atrativa, apoiando a comunicação de pessoas surdas e usuários de Libras. A abordagem utilizada na metodologia de pesquisa é do Design Science Research (DSR) e Participativo (DP). Dessa forma, conjectura-se explorar conhecimentos para melhor compreender os usuários e construir os recursos computacionais para comunicação.

\section{Comunicação e Comunicabilidade}

Para que a comunicação seja estabelecida alguns processos são envolvidos, a saber: emissor e receptor, mensagem a ser comunicada, o contexto que esta mensagem está inserida 
(lugar, tempo, valores, relações sócio-econômica e afins), o código utilizado para transmitir a mensagem. Além do significado da mensagem, está a percepção do emissor diante da mensagem, assim como a percepção do receptor, levando à ambiguidade da mensagem ou problemas de entendimento em muitos casos. As relações estabelecidas entre os interlocutores da mensagem e o seu contexto de referência podem propiciar uma comunicação lógica e objetiva (CYBIS, 2003).

Ao se relacionar com outras pessoas se faz necessário utilizar algum meio de comunicação, sendo necessária compreender os sistemas de comunicação e os mecanismos conversacionais. Os mecanismos conversacionais servem como facilitadores no fluxo da conversa e é uma das três principais categorias de mecanismos sociais usados para coordenação em SC (PREECE; ROGERS; SHARP, 2005), assim como a coordenação e a percepção, tornando possível uma relação de como os recursos e sistemas tecnológicos podem ser projetados para facilitá-los. Preece, Rogers e Sharp (2005) também colocam que esses mecanismos devem prover de estratégias para a coordenação das ações dos usuários, e os mecanismos de percepção são usados para saber o que cada qual está fazendo.

Com relação aos sistemas de comunicação, eles abrem novos horizontes, possibilitam novas formas de se comunicar e escrever, sendo necessário a troca de saberes. Dessa forma, a comunicação precisa ser eficiente, para tal, é necessário que o emissor e o receptor tenham a mesma compreensão na comunicação, ou seja, o receptor precisa compreender a comunicação da mesma forma que o emissor idealizou. Rosa (2009) observa que para uma pessoa, uma instituição ou uma nação obterem sucesso é necessário que exista uma comunicação eficaz e eficiente, apoiando e flexibilizando as comunicações e propiciando, conforme Pimentel, Gerosa e Fuks (2012, p. 67), uma conversação para ação.

O termo de conversação-para-ação nasceu com o objetivo de apoiar tanto as ações de comunicação quanto as de coordenação, ambos presentes no M3C de comunicação e utilizados nesta pesquisa. Pode-se dizer que são "um conjunto de estados" e cada vez que ocorre uma mudança de um estado para outro, ou seja, uma transição, ocorre um ato de fala (PIMENTEL; GEROSA; FUKS, 2012, p. 67-68). Segundo os autores, a compreensão da teoria dos atos de fala mudou a forma como a comunicação é vista, a informação é utilizada para realizar ações além de as transmitir.

Para que exista a conversação-para-ação ou a comunicação efetiva, se faz necessário o processo de comunicação. De acordo com Rosa (2009), para que ocorra uma comunicação de forma eficaz é necessário respeitar algumas condições a saber: (i) a comunicação é determinada pelo emissor, de acordo com sua posição, status social, reputação e experiência; (ii) o emissor não pode dizer algo de muito diferente daquilo que o receptor espera dele, caso contrário, a comunicação terá um resultado negativo; (iii) a comunicação é influenciada pela oportunidade e o momento em que dizemos algo; e (iv) uma comunicação eficiente depende de adaptar as tentativas de intercomunicação à ocasião, à situação, ao tema e às pessoas envolvidas.

Ainda relacionado com as estratégias de comunicação na conversação para ação, Libras e intérpretes de Libras são ferramentas importantes para o surdo (NASCIMENTO; FORTES; KESSLER, 2015); assim como imagens representativas. O uso de recursos tecnológicos em conjunto com as devidas estratégias fomentam o aprender de forma in- 
terativa, melhorando a comunicação entre surdo e ouvindo. Nesse sentido, Moura (2015, p. 23) observa que "[...] atividades colaborativas são importantes, pois promovem comunicação, cooperação e coordenação entre o professor e alunos, de modo a tornar o processo de ensino-aprendizagem mais produtivo.". Assim, atuam como facilitadores no processo comunicacional do surdo.

Dois conceitos nesse cenário ainda se fazem necessários e são importantes para o presente estudo, modelos de comunicação e comunicabilidade. Pode-se dizer que na busca de um modelo ideal de comunicação, cada modelo possui características próprias, elementos e formas que estes se relacionam entre si e com o todo. Independente da maneira com que o pesquisador realizará a conduta da sua pesquisa se faz necessário identificar e classificar os serviços de comunicação utilizados no sistema de comunicação.

Comunicabilidade é o meio de transmissão utilizado na comunicação aliado com uma comunicação eficiente. Não basta que o projetista apenas elabore um bom sistema, o sistema deve ser capaz de apresentar o seu funcionamento e possibilidades de interação, de forma que os usuários possam explorar o máximo de seu potencial A comunicabilidade é uma comunicação efetiva potencializada com as tecnologias, termo este em que o presente estudo está fundamentado. A comunicabilidade será realizada por meio de um recurso computacional de forma colaborativa para dispositivos móveis, que ao entrar com uma palavra possibilite que a sua saída possa ter diferentes representações como: escrita de sinais (signwriting), Libras, imagem e/ou som. A ferramenta permitirá a entrada de diferentes formatos ou representações, mas isso não significa que todos os formatos serão apresentados.

\section{Protótipo iLibras: aplicando a metodologia da pesquisa}

O conhecimento adquirido durante a condução de uma pesquisa é uma fonte de informação para a comunidade científica. Nesse sentido, Alan et al. (2004) colocam que a comunidade científica necessita de um conhecimento claro das definições, limites, ontologias, resultados de concepção e execução. Objetivando identificar formas e recursos computacionais para apoiar a comunicação da pessoa surda em conjunto com SC móveis foi realizado uma série de conjecturas embasadas na literatura das melhores práticas a serem adotadas na busca dessa solução.

O método de pesquisa utilizado neste trabalho é o Design Science Research (DSR). Para Hevner (2007), o DSR visa elevar o desempenho do resultado da pesquisa dos sistemas de informação, trazendo contribuições para a comunidade científica, sendo seu paradigma orientado à solução de um ou mais problemas específicos. Quanto a sua utilização, Hevner (2007) faz uso do DSR em sistemas de informação, sendo necessário ter a "ciência do design" e a "ciência do comportamento". O DSR possui três etapas: ambiente, DSR e Base do Conhecimento; e pode ser visto em uma junção de três ciclos reguladores de atividades relacionadas, a saber, Ciclo da Relevância, Ciclo do Design e Ciclo do Rigor.

De acordo com Hevner (2007), os produtos de pesquisa são oriundos de teorias e artefatos que produzem retorno (feedback), possibilitando o seu refinamento. Nesse sentido, foi construído um framework conceitual. No Quadro 1 pode ser visto um conjunto de diretrizes do DSR adaptadas para esta pesquisa. 
Quadro 1. Diretrizes do DSR, adaptado de Dresch, Lacerda e Júnior (2015).

\begin{tabular}{|c|c|}
\hline Diretriz & Aplicação da diretriz na pesquisa DSR \\
\hline $\begin{array}{l}\text { Relevância do } \\
\text { problema }\end{array}$ & $\begin{array}{l}\text { Moura }(2015, \text { p. } 23) \text { coloca que “[...] atividades colaborativas são impor- } \\
\text { tantes, pois promovem comunicação, cooperação e coordenação [...].”. Para } \\
\text { (TRINDADE, 2013, p. 4), "atividades colaborativas têm relevância para a } \\
\text { formação humana, social, histórica, e política e podem contribuir para a } \\
\text { construção do conhecimento e da identidade do surdo.”. No censo de } 2009 \\
\text { foram registradas } 24,5 \text { milhões de pessoas com algum tipo de deficiência } \\
\text { e } 9,7 \text { milhões possuem deficiência auditiva (DA), representando } 5,1 \% \text { da } \\
\text { população (IBGE, 2010). A presente pesquisa tem foco na comunicação } \\
\text { obtida com a tecnologia, visando ser um facilitador no processo comunica- } \\
\text { cional do surdo. }\end{array}$ \\
\hline Artefatos & $\begin{array}{l}\text { Dois artefatos produzidos. Um modelo comunicação para apoiar o processo } \\
\text { de comunicação pelas pessoas surdas e também usuários de Libras, funda- } \\
\text { mentado nas necessidades identificadas na presente pesquisa e as telas e os } \\
\text { seus componentes para dispositivos móveis para apoiar o processo comu- } \\
\text { nicacional do surdo de acordo com o modelo idealizado e as tecnologias } \\
\text { digitais e assistivas. }\end{array}$ \\
\hline $\begin{array}{ll}\text { Processo } & \text { de } \\
\text { busca } & \text { da } \\
\text { solução } & \end{array}$ & $\begin{array}{l}\text { Guiado pelo método de pesquisa DSR, conceitos de IHC, especificamente } \\
\text { do Design Centrado no Usuário ou User Centred Design (UCD), do DP e } \\
\text { do Desenho Universal (DU) para pesquisa e desenvolvimento da solução. }\end{array}$ \\
\hline $\begin{array}{l}\text { Rigor da pes- } \\
\text { quisa }\end{array}$ & $\begin{array}{l}\text { Para cada ciclo de conhecimento da pesquisa um ou mais concei- } \\
\text { tos são utilizados para garantir o rigor da pesquisa. Avaliação dos } \\
\text { especialistas, observação do uso e avaliação da utilização dos com- } \\
\text { ponentes são utilizados para garantir o rigor da pesquisa durante os } \\
\text { ciclos de design. }\end{array}$ \\
\hline Avaliação & $\begin{array}{l}\text { Avaliação de acessibilidade e usabilidade, com o envolvimento dos usuá- } \\
\text { rios utilizando a análise de observação de uso, questionários quantitativos } \\
\text { quanto a acessibilidade de comunicação do protótipo. }\end{array}$ \\
\hline $\begin{array}{l}\text { Contribuição da } \\
\text { pesquisa }\end{array}$ & $\begin{array}{l}\text { Uso do DSR na área de SC; Análise dos resultados do uso de UCD, do } \\
\text { DP no design de SC e Assistivos; Acessibilidade e Usabilidade e princípios } \\
\text { adotados do DU, Avaliação de acessibilidade junto a } 5 \text { especialistas, sendo } \\
2 \text { usuários, no Registro dos resultados obtidos sobre oportunidades no uso } \\
\text { de dispositivos móveis para facilitar a comunicação da pessoa surda e/ou } \\
\text { usuário de Libras. }\end{array}$ \\
\hline $\begin{array}{l}\text { Comunicação } \\
\text { da pesquisa }\end{array}$ & $\begin{array}{l}\text { Visa a comunidade científica interessada no desenvolvimento de SC, TDIC, } \\
\text { TA, acessibilidade comunicacional do surdo, DU e dispositivos móveis. }\end{array}$ \\
\hline
\end{tabular}

\subsection{Relevância do Problema}

No censo de 2009 foram registradas 24,5 milhões de pessoas com algum tipo de deficiência e 9,7 milhões possuem deficiência auditiva (DA), representando 5,1\% da população (IBGE, 2010). Ao se ver uma pessoa surda, normalmente não vemos ou pensamos além do som (sinal sonoro) ou da língua de sinais como meios pelos quais eles se comunicam. Se faz necessário buscar formas alternativas de comunicação disponíveis para os surdos e principalmente olhar além da língua de sinais e o dos aparelhos auditivos. A surdez não implica somente na perda de audição e das dificuldades da fala, implica também na forma que a pessoa está inserida na sociedade, na sua identidade e desenvolvimento. 
A Língua de sinais é uma linguagem visual-espacial, onde a informação é recebida de formal visual (olhos) e produzida pelas mãos. Assim como cada país que cada país ou comunidade surda apresenta sua própria língua de sinais. Ela nasce de forma natural nas Comunidades Surdas, sendo um instrumento poderoso para que se possa ter uma comunicação efetiva, elementos esses presentes na comunicação pictográfica.

Os dois artefatos criados são oriundos do fato que nesse modelo, alguns requisitos básicos se fazem necessário, a saber, (i) comunicar-se com o surdo por meio do instrumento simbólico que ele domina (Libras, escrita de sinais (signwriting), imagem, etc.); (ii) possibilitar ao surdo um modelo de convívio social vinculado à sua idade cronológica e intelectual; (iii) engajar o surdo na comunicação e na argumentação com outras pessoas; entendendo o significado das palavras; (iv) possibilitar que o surdo construa textos que exprimam suas ideias e anseios, fazendo uso da língua para diversos propósitos de acordo com seu nível de desenvolvimento cognitivo e social; (v) permitir expressar seus pensamentos por meio de diferentes recursos (Libras, escrita de sinais (signwriting), gestos, imagens, dramatização, etc.); e (vi) promover um Modelo de Comunicação Efetiva (MCE) ou Modelo de Comunicabilidade (MC) para que o surdo possa se expressar com sucesso.

Os problemas se potencializam com (i) a falta de intérpretes nas escolas e instituições; (ii) o surdo muitas vezes não compreende satisfatoriamente a língua portuguesa escrita, ocasionando uma exclusão digital, pois o mesmo não entende as páginas que acessa e navega pela internet, pelo fato de sua língua materna ser a Libras; (iii) o usuário não troca informações, mensagens e vídeos com outros usuários; (iv) o surdo possui mais de um meio de comunicação (Libras, escrita de sinais (signwriting), escrita portuguesa, gestos, etc.); (v) principalmente conforme colocado por uma das especialistas nesse estudo de Libras, que o surdo na maioria das vezes nasce em uma família de ouvintes, se a mesma conceber a surdez como doença tentará usar a língua oral como meio de comunicação e o não contato com a língua natural na comunidade em que vive (Libras), faz com que o surdo cresça com uma visão de mundo diferente dos ouvintes. Nesses casos, a pessoa surda geralmente apresenta dificuldades de estabelecer contatos interpessoais e de interação social.

\subsection{Artefatos}

Os artefatos são criados por meio de ciclos, e os ciclos se repetem até que o nível desejado seja atingido, nesse caso, o ciclo final. Cada ciclo finalizado gera uma base de conhecimento, sendo essa a base de conhecimento instanciado no próximo ciclo (HEVNER, 2007).

O presente trabalho tem foco na definição de dois artefatos de software entendíveis para a comunicação de pessoas surdas. O primeiro artefato é um MCE ou MC que foi modelado pela equipe de desenvolvimento de sistemas e aplicado ao segundo artefato produzido pela pesquisa. Um protótipo de telas e seus componentes, intitulado iLibras, sendo um facilitador na comunicação da pessoa surda. Nesse processo, conforme visto nas seções 1 e 2, para que a comunicação ocorra se faz necessário que a mensagem seja transferida e recebida por meio de um canal de comunicação. Neste trabalho, esse canal é apoiado pelo software desenvolvido, e conterá a linguagem utilizada na comunicação, forma de expressar o pensamento pela fala, escrita ou gestos e será utilizado por grande parte das interações. Assim, o contexto da pesquisa utiliza o MCE modelado visando o 
desenvolvimento de uma CA, para que os usuários na pessoa da intérprete de Libras, da coordenadora de educação da escola e do professor regente da sala possam vir a colaborar ao utilizar os artefatos de comunicação adaptadas para as telas de dispositivos móveis.

\subsection{O Rigor e o Processo de Busca da Solução}

O desenvolvimento da pesquisa foi dividido em três ciclos de design. O primeiro ciclo do design é o ciclo intitulado de "Conhecendo o usuário" (subseção 3.3.1); o segundo ciclo foi intitulado de "Ciclo do Modelo de Comunicabilidade" (subseção 3.3.2) e o terceiro ciclo foi denominado "Ciclo do Protótipo de Comunicabilidade" (subseção 3.3.3). Para cada um dos ciclos são descritas as técnicas e os métodos de avaliação utilizados, mantendo o rigor de pesquisa.

\subsubsection{Ciclo 1 do Design: Conhecendo o Usuário}

O primeiro passo do ciclo 1 do design realizado diz respeito aos usuários que irão interagir, colaborar e comunicar com pessoa surda. Nesse sentido, Hevner (2007) coloca, que em pesquisas de sistemas de informação se faz necessário conhecer os elementos relacionados com os paradigmas da "ciência do comportamento" e da "ciência do design". A ciência do comportamento diz respeito às necessidades e regras de negócio identificadas e a ciência do design aborda a pesquisa em si, do seu próprio desenvolvimento, e de como serão realizados as avaliações dos artefatos projetados.

O ciclo da ciência do comportamento na Figura 1 se refere a busca do conhecimento dos usuários, seus problemas e dificuldades, analisando os problemas na comunicação e os seus fatores influenciadores. No estudo, a ciência comportamental investiga os requisitos necessários para apoiar o uso das TA por pessoas surdas por meio do uso de dispositivos móveis e SC (seção 2). O usuário possui o conhecimento necessário para produzir o artefato, motivo pelo qual a pesquisa utilizou a abordagem de UCD, fortalecendo a estratégia de foco nas necessidades dos usuários.

A ciência do design da referida figura desenvolve, testa, avalia e refina os artefatos do MCE aplicado ao protótipo de telas e componentes de comunicação para dispositivos móveis de forma colaborativa, utilizando a abordagem da prototipação. A técnica da prototipação possibilitou verificar e validar junto ao usuário final as funcionalidades de comunicação, assim como torna possível avaliar se os artefatos produzidos de comunicação atenderão as suas reais necessidades. A última fase do ciclo, diz respeito à sua avaliação por especialistas onde é possível identificar os sucessos e fracassos dos artefatos de comunicação produzidos. Desta forma, os artefatos são projetados pela ciência do design em conformidade com as conjecturas teóricas fundamentadas pela ciência do comportamento e a avaliação do artefato produzido. Na imagem a direita da Figura 1 pode ser vista a base de conhecimento adquirido ao se fazer uso da metodologia de pesquisa do DSR na busca da solução da pesquisa, e para aquisição do mesmo foram executadas as etapas do DSR, utilizando a abordagem de UCD no referido ciclo e visando identificar (i) necessidades dos usuários; (ii) usuários; (iii) cenários de uso.

O processo de identificar as reais necessidades da pessoa surda no processo de comunicação se deu em dois momentos. No primeiro momento, foi realizada um estudo com 38 educadores (11 intérpretes de Libras e 27 professores) no estado de Santa Catarina no trabalho de (COSTA et al., 2016b), tendo esse se iniciado na pesquisa realizada 

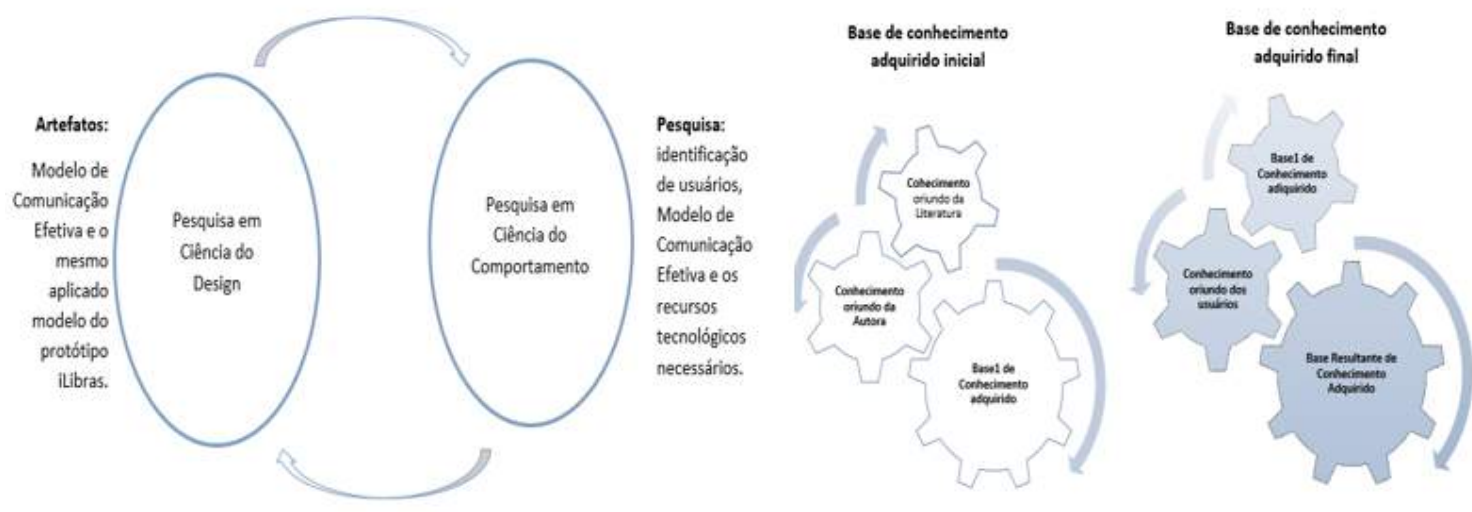

Figura 1. Ciclo do Design Science Research e Base de Conhecimento adquirido.

na literatura em (COSTA et al., 2016a). O segundo momento ocorreu após a aplicação de um questionário quantitativo de avaliação, por meio de entrevista aberta. Neste momento, a técnica teve como intuito compreender as particularidades na utilização do sistema pelo usuário. Para tal, foram envolvidos os usuários chaves da Escola Básica Municipal Leoberto Leal, do município de Blumenau, tais como: a coordenadora de educação da escola e a intérprete de Libras. A coordenadora tem uma visão de todos os interlocutores envolvidos no processo, pelo fato de ser a responsável pelos intérpretes de Libras da Escola do experimento, atuando também como professora e ter em sua sala de aula o aluno surdo. O segundo usuário chave é a intérprete de Libras, sendo ela responsável pelas atividades do aluno surdo. Assim, foi possível identificar os requisitos funcionais e não funcionais da aplicação, assim como as regras de negócio.

Com relação à identificação dos usuários, embasado nas suas necessidades foi possível identificar três classes de usuários: (i) a classe comunicador: composta pelo aluno surdo, aluno ouvinte e aluno com deficiência auditiva (cDa), que usam o aplicativo para se comunicar, relacionar e interagir; (ii) a classe coordenador: na pessoa da intérprete de Libras, responsável por coordenar quem pode colaborar para a classe comunicador; (iii) a classe cooperador: professor regente da classe, pais, diretores, coordenadora ou qualquer pessoa membro da comunidade que queira colaborar e a intérprete de Libras no papel de coordenadora permita tal cooperação.

No entendimento da visão dos diferentes usuários, suas necessidades e os possíveis cenários de uso, foi utilizada a técnica de Personas de design. Persona é uma técnica utilizada no UCD, que consiste na criação de perfis e personificação de grupo de usuários. Por meio dessa técnica foram identificados três personas: (i) cooperador: na pessoa da coordenadora e professora regente da sala; (ii) coordenador, na pessoa da intérprete de Libras; (iii) comunicador surdo: aluno surdo que fará uso do aplicativo; (iv) comunicador ouvinte: os alunos que estão na 6a série da Escola, série essa que o comunicador surdo faz parte; (v) comunicador cDA: aluno com deficiência auditiva que está na mesma série que os comunicadores (iii) e (iv), e irmão gêmeo do aluno surdo. Uma técnica mais utilizada nesta etapa, diz respeito a técnica de Diagrama de Caso de Uso (DCU) de Unified Modeling Language (UML). A técnica DCU possibilita se ter uma visão geral das funcionalidades dos sistemas e sua vinculação com os requisitos em forma de casos de uso. 
Com relação a colaboração, após a identificação dos usuários e suas necessidades decorrentes das limitações de comunicação da pessoa surda, foi possível identificar a colaboração entre eles e o aplicativo pelo M3C de colaboração. A comunicação ocorre por meio da percepção de outros usuários (chamados aqui de comunicadores) que fazem parte do grupo de "comunicadores" que se comunicam e colaboram com o dicionário iLibras; a coordenação pode ser percebida por meio do gerenciamento dos cooperadores e a cooperação pode ser percebida na criação de forma colaborativa do dicionário iLibras realizada por meio de todos os cooperadores e coordenadores que foram "autorizados" pelo coordenador. No Quadro 2 podem ser vistos alguns dos requisitos do MCE aplicado e sua relação com o M3C de colaboração.

Quadro 2. Alguns requisitos do MCE aplicado ao M3C de colaboração.

\begin{tabular}{|l|l|l|}
\hline Requisitos Funcionais (RF) & Persona MCE & M3C \\
\hline Incluir palavra nova & Colaborador & Cooperação \\
\hline Colaborar vídeo Libras & Colaborador & Cooperação \\
\hline Colaborar imagem escrita de sinais (signwriting) & Colaborador & Cooperação \\
\hline Colaborar imagem palavra & Colaborador & Cooperação \\
\hline Colaborar voz palavra & Colaborador & Cooperação \\
\hline Consultar palavra língua natural (L1) & Comunicador & Comunicação \\
\hline Autorizar Contato & Coordenador & Coordenação \\
\hline Requisitos Não Funcionais (RNF) & Persona MCE & M3C \\
\hline Relacionar aluno-ouvinte & Comunicador & Comunicação \\
\hline Relacionar intérprete-ouvinte para aprender novas palavras & Comunicador & Comunicação \\
\hline $\begin{array}{l}\text { Relacionar intérprete-ouvinte para entender algum conceito } \\
\text { por meio de uma palavra }\end{array}$ & Comunicador & Comunicação \\
\hline $\begin{array}{l}\text { Relacionar intérprete-ouvinte para compreender ou aprender } \\
\text { algum sinal }\end{array}$ & Comunicador & Comunicação \\
\hline $\begin{array}{l}\text { Relacionar intérprete-ouvinte para entender o conceito por } \\
\text { meio da imagem }\end{array}$ & Comunicador & Comunicação \\
\hline Relacionar intérprete-ouvinte por vídeo em Libras & Comunicador & Comunicação \\
\hline Relacionar no ambiente externo a escola & Comunicador & Comunicação \\
\hline $\begin{array}{l}\text { Aprender nova palavra por meio de vídeo, imagem, Libras e } \\
\text { escrita de sinais (signwriting) }\end{array}$ & Comunicador & Comunicação \\
\hline
\end{tabular}

\subsubsection{Ciclo 2 do Design: Ciclo do MCE ou MC}

O segundo ciclo do design envolve o MCE, alicerce para o Ciclo 3 do design, que se refere ao Ciclo do Protótipo de Comunicabilidade em conjunto com o M3C de colaboração e dos elementos necessários para a comunicação de pessoas surdas na comunicação. $\mathrm{Na}$ busca da solução para apoiar a comunicação da pessoa surda se faz necessário conhecer os fundamentos e conceitos mais importantes abordados na seção 2, assim como precisam ser considerados os cinco parâmetros de configuração de mãos, a saber: configuração de mãos, movimento, direção, ponto de articulação e expressão facial/corporal.

Os parâmetros se relacionam no estudo no que se refere a compreender e identificar os processos comunicacionais por meio das diferentes configurações de mãos na 
modalidade de sinais, assim como também entender a importância das diferentes modalidades, Libras e escrita de sinais (signwriting). Também se faz necessário considerar alguns pontos mais: (i) influência e "poder" que os dispositivos móveis possuem em atrair e manter pessoas, visto nas seções 1 e 2; (ii) SC; (iii) características da escrita de sinais (signwriting) e da Língua de sinais (Libras); (iv) TDIC, TA, TD e os recursos computacionais; (v) acessibilidade comunicacional; (vi) DU, desenho de interação e experiência de interface; (vii) avaliação de acessibilidade comunicacional para dispositivos níveis e para surdo; (viii) avaliação de desenho e alguns outros se faz necessário conhecer, assim como utilizar as devidas técnicas.

Na busca da identificação dos recursos computacionais móveis que apoiem o processo comunicativo da pessoa surda, se faz necessário identificar quais tipos de sistemas de modelos de comunicação que a aplicação faz uso. No presente estudo não será visto o MCE modelado, entretanto, para a pesquisa em questão é importante saber que o fluxo entre os interlocutores (emissor e receptor) da mensagem é bidirecional, ou seja, existe de fato uma comunicação efetiva.

\subsubsection{Ciclo 3 do Design: Ciclo do Protótipo de Comunicabilidade (CPC)}

O terceiro ciclo do design se refere ao "Ciclo do Protótipo de Comunicabilidade" (CPC). Esse ciclo possibilita avaliar se as interfaces idealizadas estão em conformidade com o MCE modelado e se atendem as necessidades do surdo. A técnica do DP é utilizada no referido ciclo em conjunto com outras técnicas, como as do Design de Interação (DI).

O objetivo deste ciclo é a identificação e avaliação no que diz respeito à interface do design do aplicativo iLibras, a acessibilidade de comunicação do aplicativo como meio de comunicação para o surdo e a sua navegabilidade. A tela inicial do protótipo possibilita ao usuário, das classes comunicador, coordenador e cooperador, como visto na subseção 3.3.2, ter acesso à tela principal do aplicativo iLibras, conforme apresentado na primeira tela da Figura 2. Na tela da referida figura, se tem acesso as principais funcionalidades do aplicativo, como explicitado no Quadro 2.

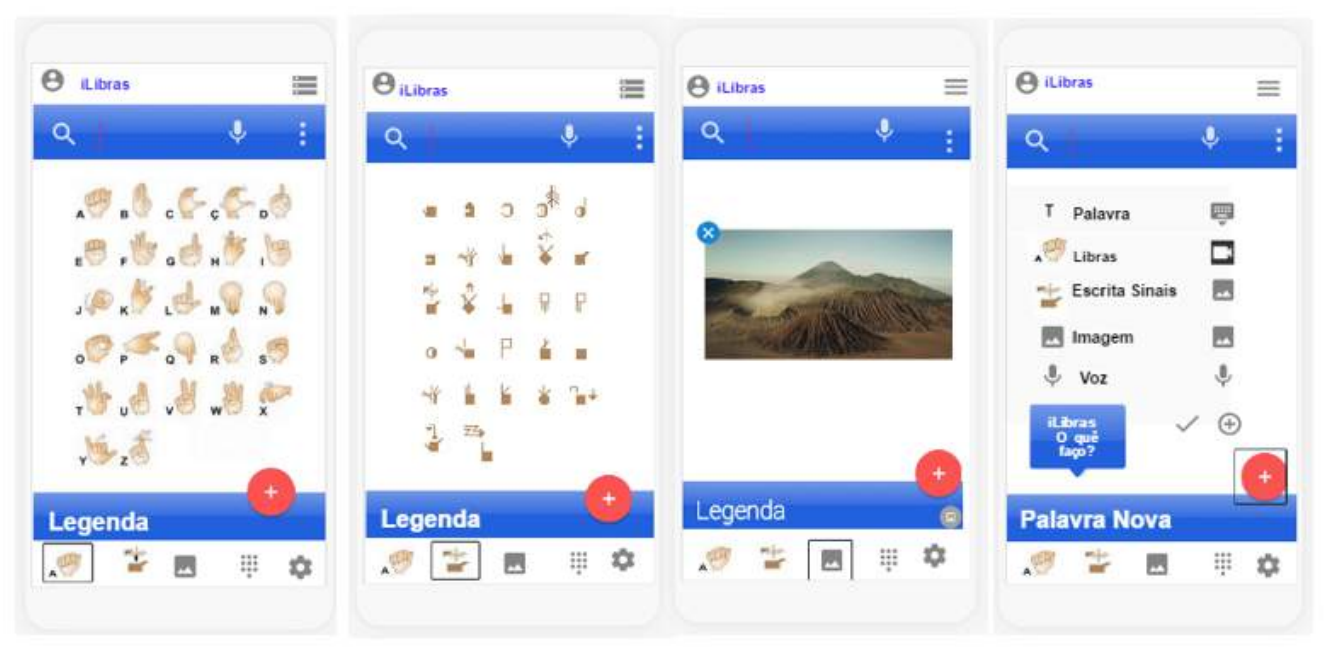

Figura 2. Telas do aplicativo iLibras. 
As funcionalidades podem ser divididas em três tipos: (i) pela classe comunicador: se refere se faz necessário fazer uma busca da palavra na língua portuguesa textual e a partir dessa consulta o resultado ser apresentado em diferentes formatos, tais como: vídeo em Libras e legenda em português (primeira tela da Figura 2); tela na escrita de sinais (signwriting) (segunda tela da Figura 2); tela da representação da palavra em forma de figura (terceira tela da Figura 2); ela pode ser ouvida pelo ícone localizado na parte superior no canto direito; (ii) pela classe cooperador: o aplicativo iLibras possibilita ao usuário ampliar seu vocabulário e trabalhar de forma colaborativa.

Para se ter acesso a essa tela é necessário ter realizado o login e ter perfil de cooperador. O acesso a essa tela pode ser feito de qualquer tela do iLibras, ao "tocar" no ícone "+" que se encontra dentro do círculo vermelho. Sua interface permite incluir nova palavra, conforme mostra a quarta tela da Figura 2. Na referida figura são apresentadas as operações para colaborar com o vídeo em Libras, com a imagem na escrita de sinais (signwriting), com a voz e com a imagem que representa a palavra; (iii) pela classe coordenador: o aplicativo possibilita ao usuário da classe coordenador, na persona de intérprete de Libras da escola, atribuir o perfil no cadastro do usuário. Somente os usuários com esse perfil e que realizarem o login no aplicativo poderão colaborar; (iv) pelas três classes: se referem as demais funcionalidades, conforme Figura 3.

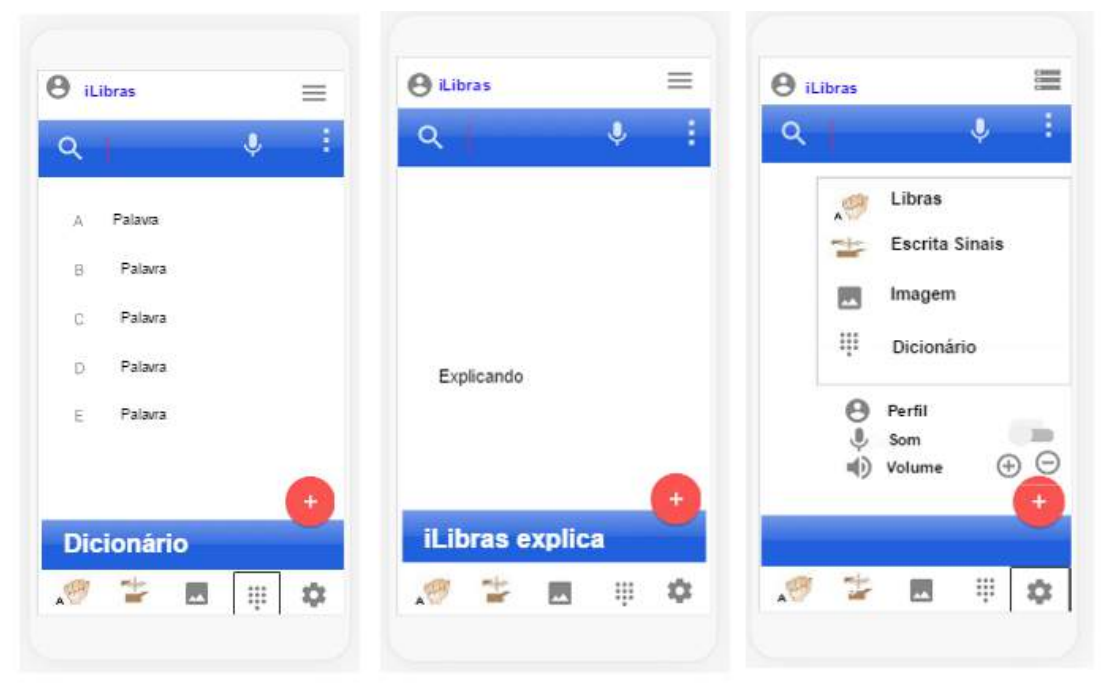

Figura 3. Telas do aplicativo iLibras.

A primeira tela da Figura 3 se refere a pesquisar no dicionário de palavras; a segunda tela se refere a tela explicativa do aplicativo iLibras; e por último a terceira tela, se refere ao menu lateral que pode ser acessado de qualquer tela, tanto pelo ícone "menu" localizado no canto superior direito quanto pelo ícone "configurações" que se encontra no canto inferior direito.

Relacionada com a condução de como ocorreu o processo de busca da solução, foi utilizada a técnica de Oficinas de Cooperação para Definição de Requisitos do DP para incluir o usuário final no processo de design. Foram utilizados os sete passos da técnica de Oficinas de Cooperação para descrever as atividades realizadas, composta por: (i) identificar as partes interessadas; (ii) identificar os problemas e as regras de negócios ou as Classes de Problemas (CP) que precisam ser resolvidas; (iii) formular a equipe; (iv) 
definição do escopo de oficinas; (v) validação do ambiente de usuário; (vi) validação da oficina; (vii) validação do escopo com as pessoas interessadas.

No início desse processo foi utilizada a técnica de protótipo visual de baixa fidelidade. Em seguida, foi usado a técnica de protótipo de maior fidelidade, onde se fez uso da ferramenta de prototipação Fluid.ui, explorando as possibilidades de experiência de usuário em conjunto com as técnicas e normas de acessibilidade comunicacional para dispositivos móveis em sistemas colaborativos. Com relação ao Desenho de Interfaces apresentadas, foi realizado um estudo dos requisitos de acessibilidade comunicacional necessários para viabilizar o apoio comunicacional do surdo, havendo uma relação entre interface de usuário, desenho universal (DU) e acessibilidade.

O conceito de DU se refere a atender todos igualmente, sem distinção, trabalhando em conjunto para que todos tenham o melhor acesso (SILVA; OSóRIO, 2009). Explicitando esse pensamento, desenvolver de forma que a pessoa com surdez tenha condições de interagir e aprender, assim como de ir e vir. O mesmo precisa estar presente desde o momento da concepção do projeto, ou seja, os desenvolvedores precisam conhecer precocemente os requisitos de acessibilidade, assim como a relação de experiência de usuário, DU e acessibilidade; pelas intersecções de cada uma das referidas áreas. Nesse sentido, foi utilizada a técnica de pesquisa das referências na literatura, relacionadas de forma direta a acessibilidade comunicacional do surdo.

Nesse sentido, foi utilizada a técnica de pesquisa das referências na literatura, relacionadas de forma direta à acessibilidade comunicacional do surdo. Houve casos de recomendações que estavam em mais de um trabalho, nesse caso, a técnica do estudo que estava redundante era excluída. As telas idealizadas na primeira fase do ciclo 3 do desenho foram projetadas e avaliadas em um segundo momento por 5 especialistas, a saber, (i) 2 especialistas em Engenharia de Software (ES), sendo 1 deles na área de SC; (ii) 1 especialista em educação de pessoa com surdez; (iii) 2 especialistas da escola onde está sendo realizado o experimento: 1 no papel de professor e coordenador das intérpretes em Libras e a intérprete de Libras.

A técnica de Oficina do DP possibilitou identificar duas situações que não estavam contempladas no aplicativo iLibras: (i) ter um campo que contemple o contexto ou significado da palavra na língua brasileira; (ii) ter busca da palavra pelo sinal. Esses foram os dois pontos que a solução prevista não contemplava. Encerrando desta forma o 3 ciclo do design.

\subsection{Avaliação}

As avaliações para os ciclos de busca da solução (subseção 3.3), são resultantes dos artefatos dos ciclos de design, sendo eles: o MCE e o MCE aplicado aos protótipos de telas do aplicativo iLibras. A avaliação consistiu em avaliar o uso das telas na experiência de usuários, a acessibilidade comunicacional e a navegabilidade de dispositivos móveis para pessoas com surdez. Foram utilizadas as técnicas de "Pesquisa exploratória", "Modelo de Avaliação visando acessibilidade de pessoa com surdez", "protótipo de alta fidelidade" para construção das telas e da navegabilidade do aplicativo e "Entrevista Aberta".

Nesse contexto, foi utilizada a técnica de "Avaliação de questionário quantitativo" com respostas "Sim" ou "Não", fazendo uso de imagens ao invés de texto pelos estudos realizados (subseção 3.3.3). O questionário utilizado nesta avaliação foi composto por 12 perguntas de forma desenho, com perguntas do tipo "Sim" ou "Não", disponibilizados 
para os papéis (seção 3.3.3). A Figura 4 apresenta na sua totalidade as questões, bem como o resultado da aplicação da avaliação. A técnica de Oficina do DP possibilitou identificar duas situações que não estavam contempladas no aplicativo iLibras: (i) a primeira diz respeito a ter um campo que contemple o contexto ou significado da palavra na língua brasileira; (ii) ter busca da palavra pelo sinal. Esses foram os dois pontos que a solução prevista não contemplava, encerrando, o ciclo 3 do design. A técnica de "Avaliação de Questionário Quantitativo", com resposta "Sim" ou "Não", possibilitou avaliar a acessibilidade comunicacional e a experiência de usuário na pessoa dos especialistas.

Algumas das recomendações adotadas estão relacionadas com a realização de questionários na avaliação para experiência de usuário em aplicativos móveis para surdos, tais como: (i) planejar com foco na acessibilidade; (ii) focar na experiência de usuário; (iii) definir papéis para o time de avaliação; (iv) elaborar e aplicar questionários voltados à acessibilidade; (v) uso de tecnologias de suporte à observação. A avaliação da acessibilidade comunicacional é encontrada na intersecção das áreas de interface de usuário, desenho universal e acessibilidade do Desenho de Interface.

A avaliação de acessibilidade comunicacional foi aplicada para 5 especialistas, sendo 2 deles especialistas no Registro dos resultados obtidos sobre oportunidades no uso de dispositivos móveis para facilitar a comunicação da pessoa surda ou usuário de Libras, e os outros 3 especialistas da educação, sendo 2 deles da educação da pessoa surda. Outro ponto identificado no estudo diz respeito que o questionário deve ser aplicado primeiro com intérprete de Libras ouvinte, devido a percepção da mesma ser diferente de uma intérprete de Libras com surdez. Com relação a elaborar e aplicar questionários voltados para acessibilidade comunicacional da pessoa surda, foi identificado que o questionário para pessoas surdas e ouvintes não devem ser o mesmo no sentido de escrita das perguntas, e as respostas devem fazer uso de emotion em Libras ao invés de texto.

Em relação a resposta, o presente estudo optou por usar emotions também no questionário de ouvinte, pelo fato de o mesmo ser aplicado em especialistas das áreas da ES, educação e educação especial, o que possibilitou avaliar com os especialistas de Libras as imagens adotadas no questionário em Entrevista Aberta após a validação dos mesmos no uso do protótipo iLibras e da aplicação do questionário quantitativo. Dos 3 especialistas de acessibilidade comunicacional do surdo, dois são especialistas da escola onde experimento está sendo realizado e a outra é uma especialista de Libras externa a escola. Dentre eles, $100 \%$ responderam "Sim" para todas as questões avaliadas. O gráfico da Figura 4 apresenta as 12 perguntas realizadas, assim como um comparativo das respostas afirmativas e das negativas.

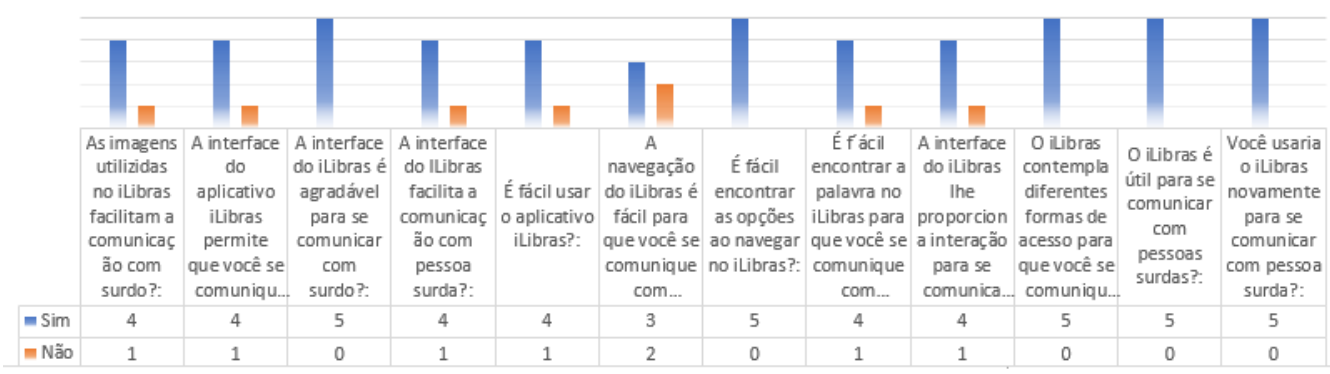

Figura 4. Resultado de avaliação de acessibilidade comunicacional. 
No que se refere aos especialistas de ES, as questões relacionadas com a acessibilidade comunicacional dos surdos tiveram respostas "Não". De acordo com eles, isso ocorreu por não serem especialistas da educação na área comunicacional do surdo, questões essas que serão avaliadas. A questão referente se é fácil usar o aplicativo foi respondida que "Não" por um especialista de ES. De acordo com esse especialista, sua avaliação negativa ocorreu pelo fato de ele não estar familiarizado com os símbolos de Libras e escrita de sinais (signwriting). É importante ressaltar que a verificação, validação e avaliação do aplicativo iLibras pelos especialistas de ES foram executadas sem nenhum tipo de instrução. As questões foram disponibilizadas e executadas por meio online sem nenhum auxílio. Após a execução dos questionários pelos 3 especialistas relacionados com Libras, foi aplicado a técnica de "Entrevista Aberta" para verificar alguma delimitação do aplicativo iLibras não abordada.

\section{Considerações finais}

Este estudo teve como objetivo apresentar uma abordagem para apoiar a comunicação de pessoas surdas por meio de ferramentas computacionais móveis e colaborativas. Nessa busca, a metodologia de pesquisa de Design Science Research (DSR) e Design Participativo (DP) se mostraram adequadas, possibilitando explorar os conhecimentos na busca de melhor compreender os usuários e construir um protótipo do Modelo de Comunicação Efetiva (MCE) aplicado ao iLibras. A pesquisa realizada neste estudo foi de cunho exploratório, pois teve como objetivo proporcionar maior familiaridade com o problema para torná-lo explícito, permitindo a construção de hipóteses ou proposições. Ou seja, a abordagem adotada na pesquisa na busca da solução que resultou em um "MCE modelado aplicado ao aplicativo iLibras" atendeu o presente estudo no sentido de que foi possível verificar o uso do aplicativo quanto a acessibilidade comunicacional da pessoa com surdez e também usuários de Libras, assim como questões de uso do aplicativo iLibras.

Com relação aos trabalhos futuros, conjectura-se detalhar os conhecimentos explorados para melhor compreender os usuários e as tecnologias assistivas para comunicação, assim como detalhar as abordagens e técnicas que guiam a pesquisa a saber, DSR; DP; Design Centrado no Usuário (UCD) e Interação (DI), no que se refere as questões relacionadas com o desenho universal; a acessibilidade e experiência do usuário, tendo em sua interseção a avaliação da acessibilidade comunicacional de pessoa com surdez para dispositivos móveis.

\section{Referências}

ALAN, R. H. V. et al. Design science in information systems research. MIS quarterly, Springer, v. 28, n. 1, p. 75-105, 2004.

COSTA, S. E. d. et al. Uma revisão sistemática da literatura para investigação de estratégias de ensino colaborativo. In: IEEE. Anais... XVIII Simpósio Brasileiro de Sistemas Colaborativos. [S.1.], 2016. p. 1537-1548.

COSTA, S. E. d. et al. Desafios na arte se ensinar inclusiva: A relação professor e intérprete na inclusão do surdo. v. 14, n. 2, 2016. Disponível em: <http: //www.seer.ufrgs.br/renote/article/view/70647>. Acesso em: 2017-05-09.

CYBIS, W. d. A. Engenharia de usabilidade: uma abordagem ergonômica. Florianópolis: Laboratório de utilizabilidade de informática, 2003. 
DRESCH, A.; LACERDA, D. P.; JÚNIOR, J. A. V. A. Design science research: método de pesquisa para avanço da ciência e tecnologia. [S.1.]: Bookman Editora, 2015. GADAMER, H.-G. Verdade e método II: complementos e índice. [S.1.]: Petrópolis: Vozes, 2002. 173-182 p.

HEVNER, A. R. A three cycle view of design science research. Scandinavian journal of information systems, v. 19, n. 2, p. 4, 2007.

IBGE. Censo demográfico 2010 - Resultados gerais da amostra. 2010. Disponível em: <http://www.ibge.gov.br/home/estatistica/populacao/censo2010/resultados \_gerais। _amostra/default $\_r e s u l t a d o s \backslash$ gerais $\backslash \_a m o s t r a . s h t m>$. Acesso em: 2017-05-10. MACHADO, L. D. P. et al. Uma abordagem colaborativa para aprendizagem de programação orientada a objetos. In: IEEE. XIII Simpósio Brasileiro de Sistemas Colaborativos. [S.1.], 2016.

MOURA, E. R. d. S. Uma ferramenta colaborativa móvel para apoiar o processo de ensino-aprendizagem da língua portuguesa para alunos surdos. $78 \mathrm{f}$. Dissertação (Mestrado em Informática) - Universidade Federal do Amazonas, Manaus, 2015, 2015.

NASCIMENTO, G. B.; FORTES, L. de O.; KESSLER, T. M. Estratégias de comunicação como dispositivo para o atendimento humanizado em saúde da pessoa surda. Saúde (Santa Maria), v. 41, n. 2, p. 241-250, 2015. Disponível em: $<$ https://periodicos.ufsm.br/index.php/revistasaude/article/view/15121>. Acesso em: 2017-02-19.

PIMENTEL, M. et al. Modelo 3c de colaboração para o desenvolvimento de sistemas colaborativo. In: III SIMPóSIO BRASILEIRO DE SISTEMAS COLABORATIVOS. Anais. [S.1.], 2006. p. 58-67.

PIMENTEL, M.; GEROSA, M. A.; FUKS, H. Capítulo 5 - sistemas de comunicação para colaboração. In: PIMENTEL, M.; FUKS, H. (Ed.). Sistemas Colaborativos. Elsevier Editora Ltda., 2012. p. 65 - 93. ISBN 978-85-352-4669-8. Disponível em: <http://www.sciencedirect.com/science/article/pii/B978853524669850005X>. Acesso em: 2017-05-10.

PREECE, J.; ROGERS, Y.; SHARP, H. Design de interação. [S.1.]: Bookman, 2005. ROSA, A. S. Comunicação: a ferramenta do profissional. Revista do Núcleo Interdisciplinar de Pesquisa e Extensão do UNIPAM, n. 6, p. 141-155, 2009. ISSN 1806-6399.

SILVA, B. D. d.; OSóRIO, A. J. As tecnologias de informação e comunicação da educação na universidade do minho. Centro de Competência da Universidade do Minho, Centro de Competência da Universidade do Minho, p. 9-25, 2009.

TRINDADE, D. InCoP: um framework conceitual para o design de ambientes colaborativos inclusivos para surdos e não surdos de cultivo de comunidades de prática. Tese (Doutorado) - Tese de Doutorado em Informática, Curitiba: Programa de Pós-Graduação em Informática do Setor de Ciências Exatas da Universidade Federal do Paraná, 2013. 